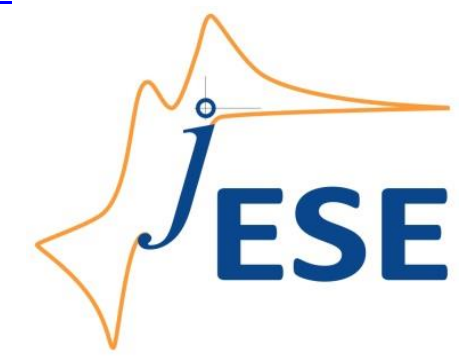

Open Access: ISSN 1847-9286

www.jESE-online.org

Original scientific paper

\title{
Experimental and theoretical study on the corrosion inhibitor potential of quinazoline derivative for mild steel in hydrochloric acid solution
}

Fidelis Ebunta Abeng ${ }^{1, \bowtie}$, Valentine C. Anadebe ${ }^{2}$, Patience Yake Nkom ${ }^{1}$, Kelechi J. Uwakwe ${ }^{3}$ and Enyinda Goodluck Kamalu ${ }^{4}$

${ }^{1}$ Material and Electrochemistry Research Group, Department of Chemistry, Cross River University of Technology. P. M. B. 1123, Calabar-Nigeria

${ }^{2}$ Chemical Engineering Department, Federal University Ndufu Alike, Ebonyi State, Nigeria

${ }^{3}$ University of Chinese Academy of Sciences, Dalian 116023, China

${ }^{4}$ Chemistry Department, Federal University of Agriculture, Makurdi, Benue State, Nigeria

Corresponding author: ${ }^{凶}$ fidelisabeng@yahoo.com, Tel.: +234 08035664813

Received: July 16, 2020; Revised: September 28, 2020; Accepted: October 3, 2020

\begin{abstract}
Interaction of metal surfaces with organic molecules has significant role in corrosion inhibition of metals and alloys. More clarification, from both experimental and computational view is needed in describing the application of inhibitors for protection of metal surfaces. In this study, the surface adsorption and corrosion inhibition behavior of metolazone, a quinazoline derivative, on mild steel in $0.02,0.04,0.06$, and $0.08 \mathrm{M} \mathrm{HCl}$ solutions were investigated. Weight loss, potentiodynamic polarization and electrochemical impedance spectroscopy techniques were used. The optimum inhibition efficiencies of 75 , 82 and $83 \%$ were found by these three techniques at the optimum inhibitor concentration of $500 \mathrm{mg} / \mathrm{L}$ and $303 \mathrm{~K}$. Scanning electron microscopy (SEM) was used to confirm adsorption of quinazoline derivative on the surface of the mild steel. Computational simulations were additionally used to give insights into the interaction between quinazoline inhibitor and mild steel surface. Thermodynamic parameters of mild steel corrosion showed that quinazoline derivative functions as the effective anti-corrosive agent that slows down corrosion process. Potentiodynamic polarization results revealed a mixed-type inhibitor, while the result of the adsorption study suggests that adsorption of the inhibitor on the mild steel surface obeys the physical adsorption mechanism and follows Langmuir adsorption isotherm model.
\end{abstract}

\section{Keywords}

Molecular modeling; acid corrosion; adsorption, mild steel surface characterization; thermodynamics 


\section{Introduction}

The extensive use of mild steel in the construction of petroleum refineries tanks, flow lines and transmission pipelines is as a result of ease of its fabrication and low cost [1]. At the other side, acid media are widely applied in the metallurgical industry for pickling and descaling of metals, chemical or electrochemical processes in oil refinery, and deactivation of equipment in atomic power establishment [2]. For solving the resulting corrosion problems for mild steel in acid environment in oil and gas industries, use of corrosion inhibitors is the best practical and cost-effective way. When added to an acidic environment in small amounts, inhibitors can appreciably reduce corrosion rates [1-3]. It has already been found that organic compounds which contain either lone pair-donating heteroatoms like $\mathrm{N}, \mathrm{O}, \mathrm{S}$ and $\mathrm{P}$, or structural moieties with $\pi$-electrons that interact with metal, demonstrate good inhibitive properties $[2,4]$. Use of these compounds, however, has recently been restricted due to their high cost and toxicity to the environment [5]. Therefore, the researchers practicing in the field of metallurgical and material industry, usually release fresh or new corrosion inhibitors, particularly those which are cheap and show highly mitigated competence and less amount of toxicity $[6,7]$.

The present investigation aims to study the corrosion protection potential of metolazone drug, i.e. quinazoline derivative (chloro-2-methyl-4-oxo-3-0-tolyl-1,2,3,4-tetrahydroquinazoline-6-sulfonamide), for mild steel in hydrochloric acid. In general, metolazone is a pharmaceutical compound applied as diuretic, for preventing high blood pressure, and for other purposes. This compound, however, contains heterocyclic molecules, $\pi$-electrons, high molecular weight and functional groups which are all indicators of good corrosion inhibitors. Many quinazoline derivatives were already investigated as corrosion inhibitors in different aggressive environments. Thus, some chlorophenyl and nitrophenyl quinazoline derivatives were used as corrosion inhibitors for carbon steel in $2 \mathrm{M} \mathrm{HCl}$ solution by Fouda et al. [8]. Al-Tamimy and Al-Majidi [9] have recognized corrosion inhibition property of 2-pentadecylquinazolinylthiourea as corrosion inhibitor for carbon steel in acidic medium. Hashim et al. [10] synthesized three new quinazoline derivatives and studied their corrosion inhibition behavior on mild steel in $\mathrm{H}_{2} \mathrm{SO}_{4}$ medium. Recently, Rbaa et al. [11] synthesized hydroxyl based quinazoline derivatives and proved excellent inhibition of corrosion at mild steel in $\mathrm{HCl}$. Chaouiki et al. [12] explored 3-cyclopropyl-3,4-dihydroquinoline-2(1H)-one as a new corrosion inhibitor for mild steel in hydrochloric acid solutions. Corrosion inhibition behavior of 2-methyl quinazoline derivative has also been investigated by Kadhim et al. [13]. Ozturk [14] synthesized and studied corrosion inhibition behavior of two quinazoline derivatives di-cationic surfactants in acidic solutions. Pradeep et al. [15] synthesized three new quinazoline derivatives and studied them as corrosion inhibitors for mild steel surface protection in $\mathrm{HCl}$ solution, using experimental and DFT methods. Fouda et al. [16] also documented quinazoline derivatives as green corrosion inhibitors for carbon steel in hydrochloric acid, employing weight loss, potentiodynamic polarization, electrochemical impedance spectroscopy and scanning electron microscopy. The results of their investigation were similar to those obtained in the present study. In the view of above findings, the present study aims to investigate metolazone drug, that is a compound derived from quinazoline substituent, as the corrosion inhibitor for mild steel in hydrochloric acid solution by means of weight loss and electrochemical techniques. In addition, some density functional theoretical (DFT) calculations are performed to locate the actual sites where inhibitor adsorption occurs on the mild steel surface. 


\section{Experimental}

\section{Materials}

Chemicals and reagents used for this study were supplied by Vickam Chemical Co Ltd, CalabarNigeria, and were of analytical grade. The commercially available mild steel sheets (Q235 steel) with purity of $98 \%$ iron and thickness of $0.008 \mathrm{~cm}$ were used for the study. The sheets were mechanically press cut into various coupons of $5 \times 4 \times 0.008 \mathrm{~cm}$ for corrosion measurement. Emery paper of different grades was used to smooth the surface of each coupon that was subsequently washed in ethanol and acetone for purification and allowed to be desiccated in air.

\section{Preparation of $\mathrm{HCl}$ solution/inhibitor stock solution}

The concentration of corrosive medium used includes $0.02,0.04,0.06$ and $0.08 \mathrm{M}$ hydrochloric acid solution. These concentrations of hydrochloric acid were prepared by diluting the appropriate volumes of analytical grade concentrated hydrochloric acid ( $37 \mathrm{wt} . \%$ ) with doubly distilled water using the standard solution formula. The inhibitor used in this study was metolazone drug of quinazoline derivative obtained from the local pharmacy (G \& I Pharmaceutical Company, Ikot Ansa CalabarNigeria) and was used without further purification. It is chemically designated as (chloro-2-methyl-4-oxo-3-0-tolyl-1,2,3,4-tetrahydroquinazoline-6-sulfonamide). The molecular formula of the studied quinazoline derivative is $\mathrm{C}_{16} \mathrm{H}_{16} \mathrm{Cl} \mathrm{N}_{3} \mathrm{O}_{3} \mathrm{~S}$ with molecular weight of $365.84 \mathrm{~g} \mathrm{~mol}^{-1}$. Appropriate concentrations from $50 \mathrm{mg} / \mathrm{L}$ to $500 \mathrm{mg} / \mathrm{L}$ of the drug were diluted into already prepared hydrochloric acid solutions [17-19].

\section{Methods}

The methods employed in this study include the weight loss, electrochemical techniques, computational simulations and scanning electron microscope, SEM.

\section{Weight loss experiments}

The mild steel coupons of known weights were suspended in $200 \mathrm{~cm}^{3}$ solution of $\mathrm{HCl}$ in $250 \mathrm{~cm}^{3}$ beakers using a Pyrex glass hook. The experiments were carried out in various concentrations of $\mathrm{HCl}$ $(0.02 \mathrm{M}, 0.04 \mathrm{M}, 0.06 \mathrm{M}$ and $0.08 \mathrm{M})$, in the absence and presence of studied inhibitor, at different temperatures $(303,313$ and $333 \mathrm{~K})$. The test solutions were maintained in a thermostatic water bath for 12 hours, after which each coupon was washed, desiccated and reweighed. The weight loss $(\Delta W)$ results were calculated from differences in two weights, that is the initial $\left(W_{1}\right)$ and final $\left(W_{2}\right)$ weight according to the eq. (1). Thereafter the corrosion rate (CR) and inhibition efficiency (IE) were evaluated using eqs. (2) and (3) [20-22].

$$
\begin{aligned}
& \Delta w=w_{1}-w_{2} \\
& \mathrm{CR}=(\Delta w / A t) 1000 \\
& \mathrm{IE}=\frac{\mathrm{CR}_{\text {blank }}-\mathrm{CR}_{\text {lnh }}}{\mathrm{CR}_{\text {blank }}} 100
\end{aligned}
$$

\section{Electrochemical measurements}

All electrochemical measurements were performed with the aid of a potentiostat/galvanostat. Platinum wire, saturated calomel electrode (SCE) and mild steel coupon of exposed surface area of $1 \mathrm{~cm}^{2}$, were used as counter, reference and working electrode, respectively. The electrochemical experiments were performed in $0.02 \mathrm{M} \mathrm{HCl}$ solution, after 30 minutes immersion in the test solution at room temperature. Polarization measurements were carried out from +250 to $-250 \mathrm{mV}$ vs. 
corrosion potential ( $\left.E_{\text {corr }}\right)$ at the scan rate of $0.5 \mathrm{mV} \mathrm{s}^{-1}$. EIS measurement was performed using potentiostat/galvanostat in the frequency range of $100 \mathrm{kHz}$ to $0.05 \mathrm{~Hz}$ with the signal amplitude of $5 \mathrm{mV}[23-25]$.

\section{Scanning electron microscopy (SEM)}

The morphological analysis of the corroded coupons was carried out at Chemical Engineering Department Ahmadu Bello University, Zaria, using the scanning electron microscopy SEM (Model MVE016477830, Manufactured by Phenom-world Eindhoven, The Netherlands). SEM images were taken after one day immersion of mild steel coupons in $0.02 \mathrm{M} \mathrm{HCl}$ solution in the absence and presence of the inhibitor at room temperature.

\section{Computational chemistry study}

Density functional theory (DFT) methods of 4.0 material studio software were used in performing the quantum chemical modeling of the present study. This is because DFT method is less time consuming and less expensive from computational point of view. The calculations were done using the Becke's Three Parameter Hybrid method (B3) applying the correlation functional of Lee Yang and Parr (LYP) (DFT/B3LYP).

\section{Results and discussion}

\section{Weight loss}

Corrosion rates of mild steel in different concentrations of hydrochloric acid, based on weight loss measurements are presented in Table 1.

Table 1. Corrosion rates and inhibition efficiencies for mild steel in various concentrations of $\mathrm{HCl}$ with and without inhibitor, obtained from weight loss measurements.

\begin{tabular}{|c|c|c|c|c|c|c|c|c|}
\hline \multirow{3}{*}{$c_{\text {inh }} / \mathrm{mg} \mathrm{L}^{-1}$} & \multicolumn{8}{|c|}{$\mathrm{CHCl}_{\mathrm{HC}} / \mathrm{M}$} \\
\hline & 0.02 & 0.04 & 0.06 & 0.08 & 0.02 & 0.04 & 0.06 & 0.08 \\
\hline & \multicolumn{4}{|c|}{ Corrosion rate, $\times 10^{-4} \mathrm{mg} \mathrm{cm}^{-2} \mathrm{~h}^{-1}$} & \multicolumn{4}{|c|}{ Inhibition efficiency, \% } \\
\hline & \multicolumn{8}{|c|}{$303 \mathrm{~K}$} \\
\hline Blank & 9.3 & 13.4 & 15.8 & 18.7 & & & & \\
\hline 50 & 7.0 & 10.6 & 12.4 & 16.2 & 24.8 & 20.9 & 16.4 & 13.2 \\
\hline 100 & 6.0 & 9.3 & 10.3 & 13.7 & 35.2 & 30.4 & 30.1 & 26.6 \\
\hline 200 & 5.1 & 8.1 & 9.7 & 12.9 & 44.7 & 39.4 & 33.7 & 31.2 \\
\hline 300 & 4.2 & 6.3 & 7.4 & 10.4 & 54.6 & 52.7 & 48.0 & 44.4 \\
\hline \multirow[t]{2}{*}{500} & 2.3 & 4.7 & 5.5 & 8.5 & 75.2 & 64.9 & 59.9 & 54.8 \\
\hline & \multicolumn{8}{|c|}{$313 \mathrm{~K}$} \\
\hline Blank & 13.2 & 20.3 & 25.8 & 28.6 & & & & \\
\hline 50 & 10.1 & 16.1 & 20.9 & 24.2 & 23.3 & 20.6 & 19.0 & 15.4 \\
\hline 100 & 8.5 & 14.0 & 18.3 & 22.3 & 35.5 & 31.0 & 29.1 & 22.0 \\
\hline 200 & 6.1 & 10.3 & 13.2 & 17.4 & 53.7 & 49.2 & 48.8 & 39.2 \\
\hline 300 & 3.9 & 8.0 & 10.9 & 14.1 & 70.4 & 60.4 & 57.8 & 50.7 \\
\hline \multirow[t]{2}{*}{500} & 1.9 & 5.2 & 7.0 & 11.4 & 85.8 & 74.5 & 72.8 & 60.1 \\
\hline & \multicolumn{8}{|c|}{$333 \mathrm{~K}$} \\
\hline Blank & 17.0 & 23.2 & 27.0 & 32.1 & & & & \\
\hline 50 & 13.2 & 18.1 & 22.6 & 27.4 & 22.4 & 22.0 & 16.3 & 14.3 \\
\hline 100 & 10.1 & 15.0 & 18.4 & 23.1 & 40.6 & 35.3 & 31.9 & 27.7 \\
\hline 200 & 9.2 & 14.7 & 18.0 & 21.9 & 45.7 & 36.6 & 33.3 & 31.5 \\
\hline 300 & 6.1 & 12.4 & 15.2 & 19.6 & 64.0 & 46.6 & 43.7 & 38.6 \\
\hline 500 & 4.4 & 8.3 & 11.8 & 15.3 & 73.9 & 64.1 & 56.3 & 52.0 \\
\hline
\end{tabular}


It is clearly seen that corrosion rate of mild steel increases with increase in the concentration of hydrochloric acid solution and decreases as the concentration of inhibitor increases. These results indicate an inhibitive potential of quinazoline derivative on mild steel corrosion. The inhibition efficiencies at various concentrations of $\mathrm{HCl}$ with concentrations of quinazoline derivative as inhibitor, were measured at different temperatures (303, 313 and 323K) and listed in Table 1. Results from Table 1 show that the corrosion inhibition efficiency of quinazoline derivative on mild steel in hydrochloric acid increases with increased concentration of the studied inhibitor. Also, inhibition efficiency decreases with a decrease in the concentration of the acid. This is because at higher concentrations of the corrodent, the inhibitor is attacked by the acid leading to reduction of the inhibitor effectiveness [26-28].

\section{Effect of temperature- thermodynamic/adsorption study}

The assessment of thermodynamic parameters is of great importance in the analysis of inhibitors adsorption on the metal surface. The thermodynamic parameters for the studied system were estimated using the following equations:

$$
\begin{aligned}
& \mathrm{CR}=K e^{\left(-E_{a} / R T\right)} \\
& \mathrm{CR}=\frac{R T}{N h} \mathrm{e}^{\left(\frac{\Delta S_{\mathrm{a}}}{R}\right)} \mathrm{e}^{\left(\frac{\Delta H_{\mathrm{a}}}{R T}\right)}
\end{aligned}
$$

In eq. (4), $E_{\mathrm{a}}$ is activation energy of corrosion reaction, $K$ is Arrhenius constant, $R$ is gas constant and $\mathrm{T}$ is absolute temperature. In eq. (5), $N, h, \Delta S_{\mathrm{a}}$ and $\Delta H_{\mathrm{a}}$ are Avogadro number, Planck constant, activation entropy change, and activation enthalpy change, respectively. The plots of log CR and $\log (C R / T)$ as functions of the inverse of temperature are illustrated in Figure 1, showing straight lines with linear regression coefficients close to unity for all inhibitor concentrations studied. The values of thermodynamic parameters for mild steel corrosion $\left(E_{\mathrm{a}}, \Delta H_{\mathrm{a}}\right.$ and $\left.\Delta S_{\mathrm{a}}\right)$ are calculated from the slopes and intercepts of linear relationships in Figure 1 and are presented in Table 2.
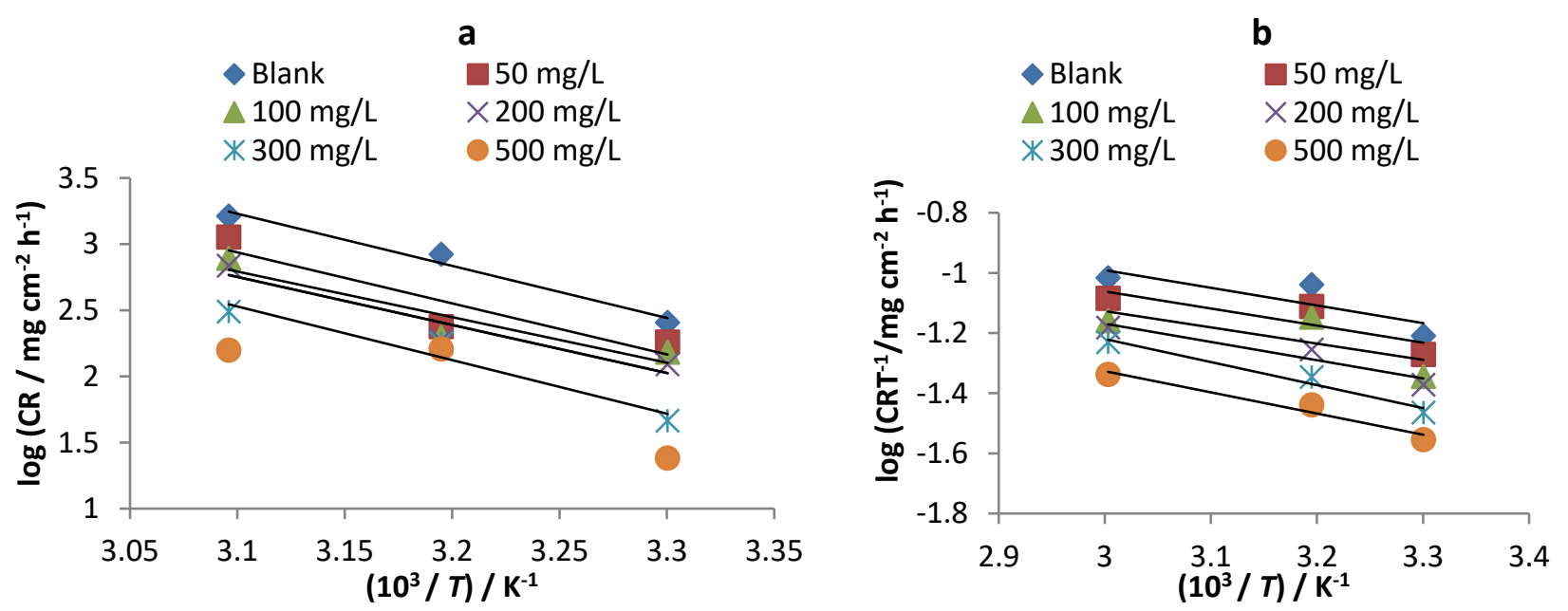

Figure 1. (a) Arrhenius plots and (b) transition state plots for mild steel in $0.02 \mathrm{M} \mathrm{HCl}$ without and with different concentrations of quinazoline derivative inhibitor.

Data in Table 2 revealed that the apparent $E_{\mathrm{a}}$ value for corrosion in the blank solution is $60.2 \mathrm{~kJ} \mathrm{~mol}^{-1}$, while in the presence of the quinazoline derivative, $E_{\mathrm{a}}$ values range from 62 to $75 \mathrm{~kJ} \mathrm{~mol}^{-1}$. It is evident that $E_{\mathrm{a}}$ is higher in the solution with inhibitor than in the blank one. According to Fouda et al. [8], higher $E_{\mathrm{a}}$ value in presence of inhibitor indicates the physical adsorption mechanism of inhibitor on the mild steel surface. The increase in $E_{a}$ value can also be 
attributed to a noticeable decrease in the adsorption of the inhibiting molecules on the metallic surface with an increase in temperature [8]. This suggests that the energy barrier of the corrosion reaction rises in the presence of the quinazoline derivative [28]. The positive sign of enthalpy $\left(\Delta H_{\mathrm{a}}\right)$ values is principally associated with endothermic nature of corrosion of mild steel, indicating slow dissolution of mild steel in the presence of the quinazoline derivative [8,28]. Increase of $\Delta H_{\mathrm{a}}$ values with increase of inhibitor concentration suggests slower dissolution of mild steel, or higher protective ability of inhibitor. As reported in Table 2 , the increase of negative values of $\Delta S_{\text {a }}$ reflects an association rather than a dissociation step. This implies that a decrease in disorder occurs when reactants are transferred to the activated complex [28].

Table 2. Thermodynamic parameters for mild steel corrosion in $0.02 \mathrm{M} \mathrm{HCl}$ at different concentrations of quinazoline derivative inhibitor.

\begin{tabular}{cccccc}
\hline$c_{\text {inh }} / \mathrm{mgL}^{-1}$ & $E_{\mathrm{a}} / \mathrm{kJ} \mathrm{mol}^{-1}$ & $\mathrm{R}^{2}$ & $\Delta H_{\mathrm{a}} / \mathrm{kJ} \mathrm{mol}^{-1}$ & $R^{2}$ & $\Delta S_{\mathrm{a}} / \mathrm{Jmol}^{-1} \mathrm{k}^{-1}$ \\
\hline Blank & 60.2 & 0.966 & 49 & 0.699 & -0.769 \\
\hline 50 & 59 & 0.802 & 47 & 0.722 & -0.642 \\
\hline 100 & 56 & 0.651 & 45 & 0.542 & -0.490 \\
\hline 200 & 62 & 0.941 & 50 & 0.913 & -0.652 \\
\hline 300 & 75 & 0.979 & 64 & 0.971 & -1.076 \\
\hline 500 & 70 & 0.970 & 59 & 0.958 & -0.786 \\
\hline
\end{tabular}

\section{Potentiodynamic polarization}

Figure 2 presents anodic and cathodic polarization curves of mild steel corrosion in $0.02 \mathrm{M} \mathrm{HCl}$ in the absence and presence of quinazoline derivative inhibitor. The polarization plots indicate that anodic and cathodic reactions in the blank acid solution and in solutions containing inhibitor follow Tafel's law. The inhibited solution, however, produced a pronounced effect by shifting $E_{\text {corr }}$ into anodic direction, and decreasing anodic and cathodic current density values. This indicates that quinazoline derivative is a mixed-type inhibitor with predominant anodic effect. The corresponding polarization parameters namely, corrosion current density $\left(j_{\text {corr }}\right)$ corrosion potential $\left(E_{\text {corr }}\right)$, anodic and cathodic Tafel slopes $\left(\beta_{\mathrm{a}}\right.$ and $\beta_{\mathrm{c}}$ ) were determined from Figure 2 and listed in Table 3 . The increase in the inhibitor concentration decreases $j_{\text {corr }}$ and $E_{\text {corr }}$ values due to adsorption of inhibitor molecules on the mild steel surface, which slows down corrosion reaction.

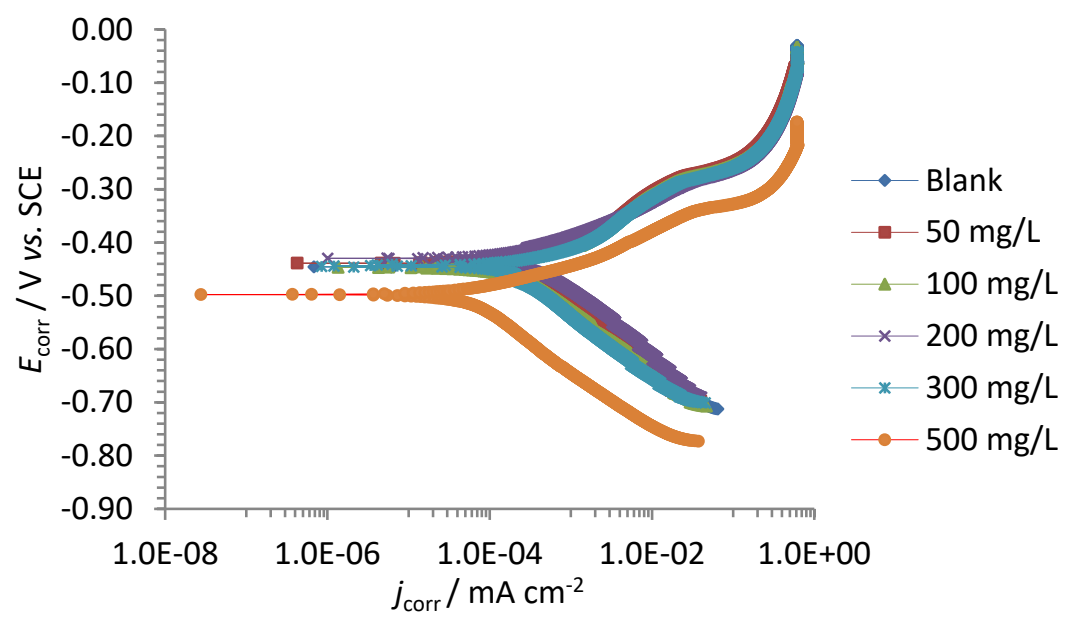

Figure 2. Potentiodynamic polarization plots of mild steel in $0.02 \mathrm{M} \mathrm{HCl}$ in absence and presence of various concentrations of quinazoline derivative inhibitor.

The Tafel constants $\left(\beta_{\mathrm{a}}\right.$ and $\beta_{\mathrm{c}}$ ) decreased with the increasing quinazoline derivative concentration, showing that quinazoline derivative controls both the anodic and cathodic reaction, but it is clearly seen 
in Fig. 2 that the Tafel plots are been sweep into the direction of the positive sites (anodic sites). The inhibition efficiency was calculated from polarization data by the equation [19,29-31]:

$$
\mathrm{IE}=\left(\frac{j_{\text {corr(blank) }}-j_{\text {corr(inh) }}}{j_{\text {corr(blank) }}}\right) 100
$$

where $j_{\text {corr(blank) }}$ and $j_{\text {corr(inh) }}$ are the corrosion current density in the absence and presence of the inhibitor, respectively.

Table 3. Polarization and Tafel parameters for mild steel in $0.02 \mathrm{M} \mathrm{HCl}$ in the absence and presence of various concentrations of quinazoline derivative inhibitor.

\begin{tabular}{cccccc}
\hline$c_{\text {inh }} / \mathrm{mg} \mathrm{L}^{-1}$ & $-E_{\text {corr }} / \mathrm{mV}$ & $j_{\text {corr }} / \mu \mathrm{A} \mathrm{cm}^{-2}$ & $\beta_{\mathrm{c}} / \mathrm{mV} \mathrm{dec}^{-1}$ & $\beta_{\mathrm{a}} / \mathrm{mV} \mathrm{dec}^{-1}$ & $\mathrm{IE} / \%$ \\
\hline Blank & 466 & 580 & 113 & 97 & \\
\hline 50 & 424 & 453 & 105 & 85 & 21.9 \\
\hline 100 & 419 & 280 & 100 & 78 & 51.7 \\
\hline 200 & 410 & 253 & 89 & 80 & 56.4 \\
\hline 300 & 409 & 222 & 84 & 82 & 61.7 \\
\hline 500 & 403 & 100 & 79 & 73 & 82.8 \\
\hline
\end{tabular}

\section{Electrochemical impedance spectroscopy}

Impedance spectra exemplified by Nyquist plots obtained for mild steel in $0.02 \mathrm{M} \mathrm{HCl}$ solution in the absence and presence of various concentrations of quinazoline derivative are illustrated in Figure 3a. Depressed semicircles are generally seen in $0.02 \mathrm{M} \mathrm{HCl}$ solution over the frequency range studied, becoming smaller with increase of the inhibitor concentration. The electrochemical equivalent circuit (EEC) employed to evaluate impedance parameter values is shown in Figure $3 \mathrm{~b}$. This EEC is composed from few elements due to the solution resistance $\left(R_{s}\right)$, charge transfer resistance of the interfacial corrosion reaction $\left(R_{\mathrm{ct}}\right)$ and the constant phase element $(\mathrm{CPE})$ due to double-layer impedance. Impedance of CPE ( $\left.Z_{\mathrm{CPE}}\right)$ is defined as $[19,20,32-34]$ :

$$
Z_{\mathrm{CPE}}=Q_{\mathrm{dl}}^{-1}(j \omega)^{-n}
$$

a

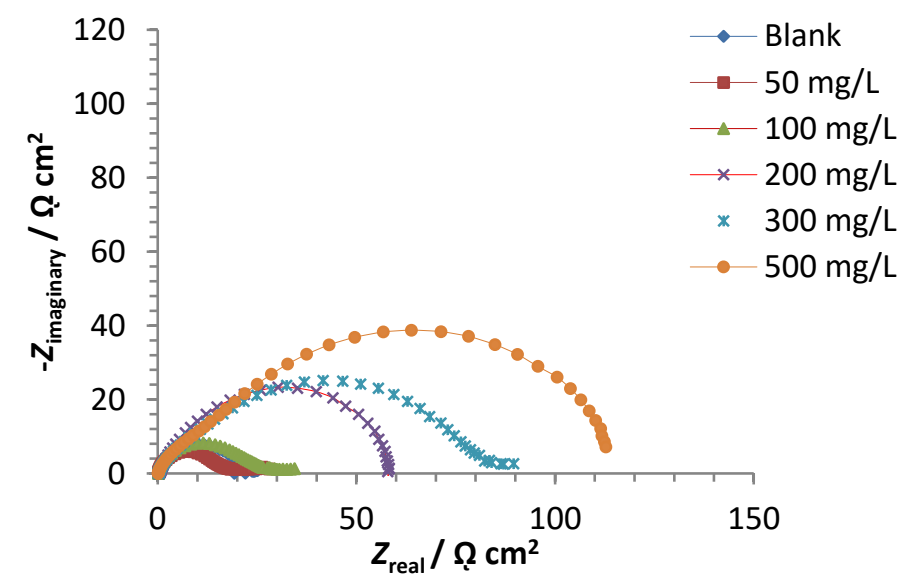

b

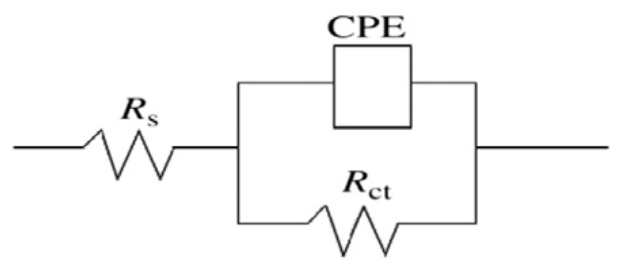

Figure 3. (a) Nyquist impedance spectra of mild steel corrosion in $0.02 \mathrm{M} \mathrm{HCl}$ in absence and presence of quinazoline derivative; (b) EEC used for EIS data fittings.

$Z_{\mathrm{CPE}}$ is described by two frequency independent parameters $Q_{\mathrm{dl}}$ and $n, j^{2}=-1$ while $\omega$ is angular frequency of measurement ( $\omega=2 \pi f$, where $f$ represents frequency in $\mathrm{Hz}$ ). $Q_{\mathrm{dl}}$ is related to doublelayer capacitance $\left(C_{\mathrm{dl}}\right)$, and $n$ is the shifting parameter from ideal capacitive response due to the nature of the solid (mild steel) surface. The electrode impedance parameter values $\left(R_{\mathrm{ct}}, Q_{\mathrm{dl}}, n\right)$, obtained by fitting EEC (Figure 3b) to measured impedance data (Figure 3a) are listed in Table 4. 
Data in Table 4 show that $R_{\mathrm{ct}}$ values, determined by the diameters of semicircles in Figure $3 a$, increase with increase in the concentration of inhibitor, with a corresponding decrease of $Q_{\mathrm{dl}}\left(C_{\mathrm{dl}}\right)$ values. These observations are attributed to adsorption of quinazoline derivative molecules directly onto the metal surface, preventing thus metal dissolution [32,33].

Table 4. Electrochemical impedance parameter values of mild steel in $0.02 \mathrm{M} \mathrm{HCl}$ in absence and presence of different concentrations of quinazoline derivative inhibitor.

\begin{tabular}{ccccc}
\hline$c_{\text {inh }} / \mathrm{mg} \mathrm{L}^{-1}$ & $R_{\mathrm{ct}} / \Omega \mathrm{cm}^{2}$ & $Q_{\mathrm{dl}} / 10^{-3} \Omega^{-1} \mathrm{~s}^{n} \mathrm{~cm}^{-2}$ & $n$ & $\mathrm{IE} / \%$ \\
\hline Blank & 20.10 & 219 & 0.89 & -- \\
\hline 50 & 25.56 & 170 & 0.87 & 21.4 \\
\hline 100 & 30.02 & 150 & 0.85 & 33.0 \\
\hline 200 & 34.52 & 130 & 0.86 & 41.7 \\
\hline 300 & 68.20 & 66 & 0.86 & 70.5 \\
\hline 500 & 120.40 & 40 & 0.87 & 83.3 \\
\hline
\end{tabular}

The values of $n$ are in the range of 0.85 to 0.89 , signifying non ideal capacitive character which can be attributed to heterogeneity of the metal surface. If $n$ values are reduced gradually with increase in the inhibitor concentration, this would be due to adsorption of the studied molecule on the steel surface [6,35]. In EIS measurements, the inhibition efficiency of quinazoline derivative is usually calculated using the following equation:

$$
\mathrm{IE}=1-\frac{R_{\mathrm{ct}(\text { blank) }}}{R_{\mathrm{ct}(\text { inh })}} 100
$$

where $R_{\mathrm{ct}(\text { blank) }}$ and $R_{\mathrm{ct}(\mathrm{inh})}$ are charge transfer resistances for blank and inhibitor solution, respectively.

\section{Adsorption considerations}

The mode of adsorption of quinazoline derivative inhibitor molecules on the mild steel surface was examined by different adsorption isotherm models. The model that best fitted adsorption behavior of the studied inhibitor was Langmuir adsorption isotherm, evaluated using the following equation:

$$
c / \theta=1 / K_{\text {ads }}+c
$$

In eq. (9), $c$ is inhibitor concentration in the bulk electrolyte, $\theta$ is degree of surface coverage equal to IE/100, while $K_{\text {ads }}$ is the equilibrium constant of adsorption-desorption process obtained from the reciprocal intercepts of straight lines in Figure 4 [36].

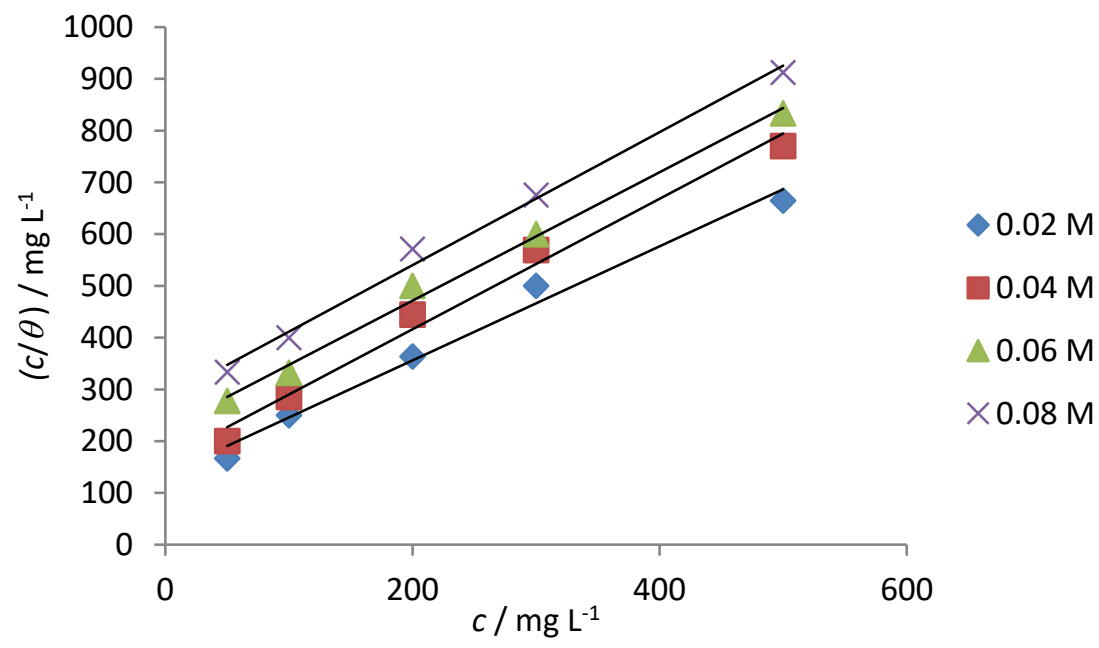

Figure 4. Langmuir adsorption isotherm for quinazoline derivative inhibitor on mild steel surface in different concentrations of $\mathrm{HCl}$ solution. 
The change of Gibbs free energy of adsorption $\left(\Delta G_{\text {ads }}\right)$ of the studied inhibitor molecules on mild steel surface was evaluated using the equation $[6,22]$ :

$$
\Delta G_{\text {ads }}=-2.303 R T \log \left(55.5 K_{\text {ads }}\right)
$$

The values of $\Delta G_{\text {ads }}$ calculated by eq. (10) are listed in Table 5 for each concentration of the acid used, at different temperature values $(303,313,323 \mathrm{~K})$. Negative signs of $\Delta G_{\text {ads }}$ are obtained, and the values of $-\Delta G_{\text {ads }}$ are less than $-20 \mathrm{~kJ} \mathrm{~mol}^{-1}$, which are within the range of values that supports the mechanism of physical adsorption [37-39].

Table 5. $\Delta \mathrm{G}_{\text {ads }}$ values for adsorption of the studied inhibitor on mild steel in different concentrations of $\mathrm{HCl}$ solution and temperature range of $303-333 \mathrm{~K}$.

\begin{tabular}{|c|c|c|c|c|}
\hline \multirow{3}{*}{$T / \mathrm{K}$} & \multicolumn{4}{|c|}{$C_{\mathrm{HCl}} / \mathrm{M}$} \\
\hline & 0.02 & 0.04 & 0.06 & 0.08 \\
\hline & \multicolumn{4}{|c|}{$\Delta G_{\text {ads }} / \mathrm{kJ} \mathrm{mol}^{-1}$} \\
\hline 303 & -14.1 & -15.2 & -16.8 & -18.6 \\
\hline 313 & -16.8 & -17.2 & -18.0 & -19.7 \\
\hline 333 & -16.2 & -15.0 & -17.5 & -18.5 \\
\hline
\end{tabular}

\section{Computational chemistry study}

The molecular properties of the studied inhibitor, i.e. quinazoline derivative compound were examined by quantum chemical calculations in order to provide a theoretical background for the experimental results $[40,41]$. Figure 5 shows the optimized molecular structure, the highest occupied molecular orbital (HOMO) and the lowest unoccupied molecular orbital (LUMO), of the studied molecule. The mechanism of adsorption on the metal surface involves donation and acceptance of electrons between the molecule and metal surface. HOMO orbital is associated with donation of electrons, while LUMO orbital is associated with acceptance of electrons $[15,26,42]$.

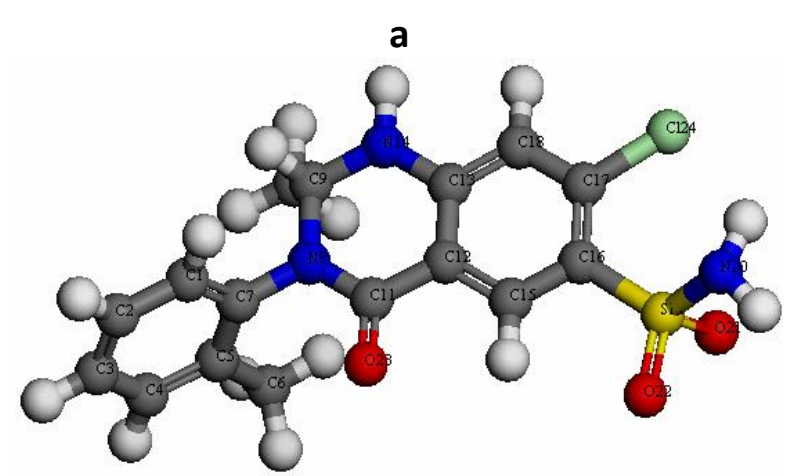

C

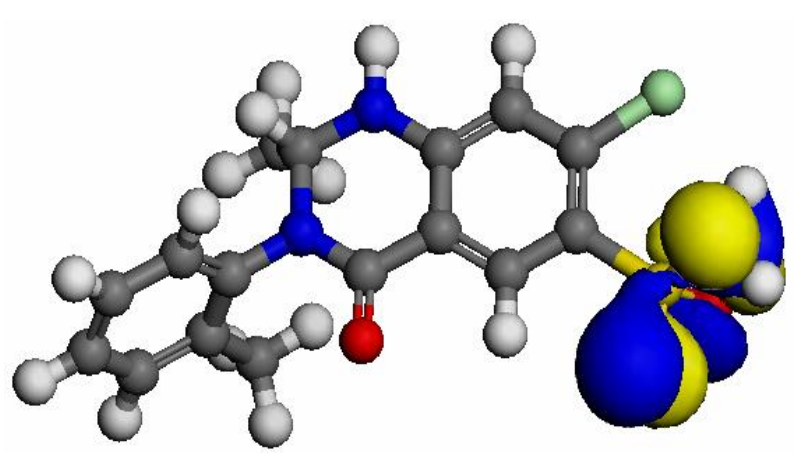

b

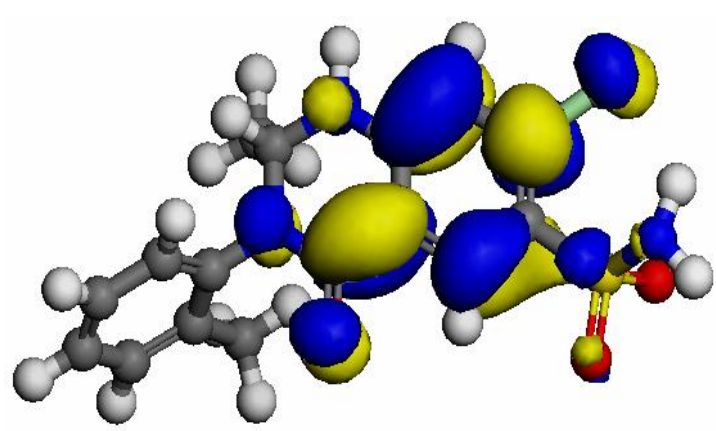

d

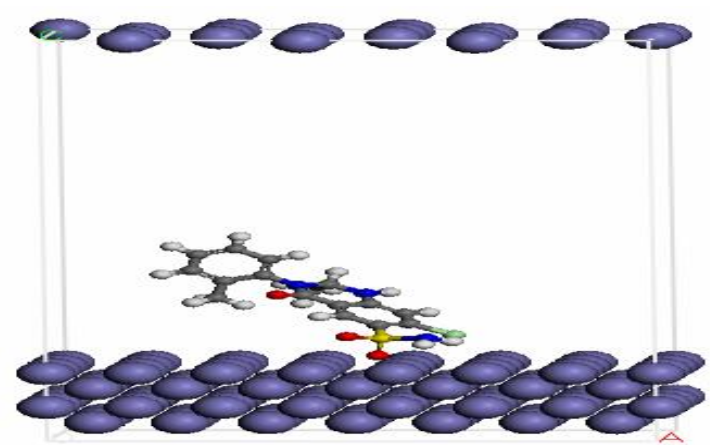

Figure 5. (a) Optimized structure, (b) HOMO, (c) LUMO, and (d) molecular dynamic simulation of the inhibitor molecule on Fe surface. Atom legend: white $=\mathrm{H}$; gray $=\mathrm{C}$; red $=O$; blue $=N$.

The results of important quantum chemical parameters of the studied molecule are presented in Table 6 . These parameters are of primarily importance because they relate molecular species 
toward adsorption $[4,6,35,36]$. The energy barrier that must be overcome before an electron moves from HOMO to LUMO level is described by the energy gap ( $\Delta E=E_{\text {LUMO- }} E_{\text {HOMO }}$ ). Usually, lower energy gap $(\Delta E)$ indicates good adsorption ability and hence good inhibition efficiency, because lower activation energy will be required to move an electron from the lowest occupied orbital $[43,44]$. Calculations of the quantum chemical parameters like ionization potential (IP) and electron affinity (EA) were done by following equations:

$$
\begin{aligned}
& \mathrm{IP}=-E_{\text {HOMO }} \\
& \mathrm{EA}=-E_{\text {LUMO }}
\end{aligned}
$$

Electronegativity $(\chi)$ and the absolute hardness $(\eta)$ values according to the theory of Pearson are given by the equations:

$$
\begin{gathered}
\chi=\frac{I E+E A}{2} \\
\eta=\frac{I E-E A}{2}
\end{gathered}
$$

\begin{tabular}{|c|c|c|c|c|c|c|c|c|c|}
\hline$E_{\text {HOMO }} / \mathrm{eV}$ & $E_{\text {LUMO }} / \mathrm{eV}$ & $\Delta E / \mathrm{eV}$ & IP / eV EA / eV & $\chi / \mathrm{eV}$ & $\eta / \mathrm{eV}$ & $\sigma / \mathrm{eV}^{-1}$ & $\Delta N$ & $\omega / \mathrm{eV}$ & $\mu / \mathrm{D}$ \\
\hline-5.377 & -2.605 & 2.772 & 5.377 & 3.991 & 1.386 & 0.721 & 1.085 & 5.746 & 10.823 \\
\hline
\end{tabular}

Table 6. Calculated values of quantum chemical parameters of the studied inhibitor.

The inverse of global hardness gives global softness $(\sigma)$ :

$$
\sigma=\frac{1}{\eta}=-\frac{2}{E_{\text {Hомо }}-E_{\text {LUMO }}}
$$

The fraction of electrons transfer $(\Delta N)$ from the inhibitor molecule to the metal surface is estimated using the equation:

$$
\Delta N=\frac{\chi_{\mathrm{M}}-\chi_{\text {inh }}}{2\left(\eta_{\mathrm{M}}+\eta_{\text {inh }}\right)}
$$

where $\chi_{M}$ and $\chi_{\text {inh }}$ represent electro-negativity of metal and inhibitor, while $\eta_{M}$ and $\eta_{\text {inh }}$ are the absolute hardness of metal (Fe atoms) and inhibitor, respectively. The theoretical value of $\chi_{\mathrm{M}}$ for bulk metal is given as $7 \mathrm{eV}$, while $\eta_{\mathrm{M}}=0 \mathrm{eV}$. Note also, that the electrophilicity index $(\omega)$ has recently been defined as $[15,43,45]$ :

$$
\omega=\frac{\chi^{2}}{2 \eta}
$$

When $\Delta N>0$, electron transfer takes place from inhibitor molecule to the metal surface. Also, the electron donating ability of an inhibitor molecule is increased when $\Delta N<3.6$ [42-44,46]. Dipole moment $(\mu)$ is mostly used for the prediction of corrosion inhibition efficiency, because it measures the polarity of a bond and is related to the electron distribution in a molecule. The higher is the dipole moment of an inhibitor, the stronger is the dipole-dipole interaction of the inhibitor with metal surface. This also indicates that the dipole moment reflects in higher inhibition efficiency [46]. This discussion is in line with the present study, because all calculated quantum chemical parameter values of this study given in Table 6 , are within the acceptable range of values already reported for some excellent corrosion inhibitors [6,43-45].

Quantum chemical parameters presented in Table 6 are global reactivity descriptors that describe the system as a whole. For analyzing local selectivity of inhibitor molecule, other descriptors should be used. In principle, Fukui function shows the regions that gain or lose electron upon nucleophilic or electrophilic attacks. Fukui function itself is based on the fact that if $\mathrm{N}$-electron 
system gains electron, it becomes $\mathrm{N}+1$ electron system, while $\mathrm{N}-1$ electron system means electron loss. Based on this concept, three types of Fukui function are known, i.e. electrophilic Fukui function $\left(f^{-}\right)$when it loses electron, nucleophilic Fukui function $\left(f^{+}\right)$when it gains electron and Fukui function for radical attack $\left(f^{\circ}\right)[6,46,47]$. Calculated values of condensed electrophilic, nucleophilic Fukui functions and bond lengths calculated by DFT method are listed in Table 7.
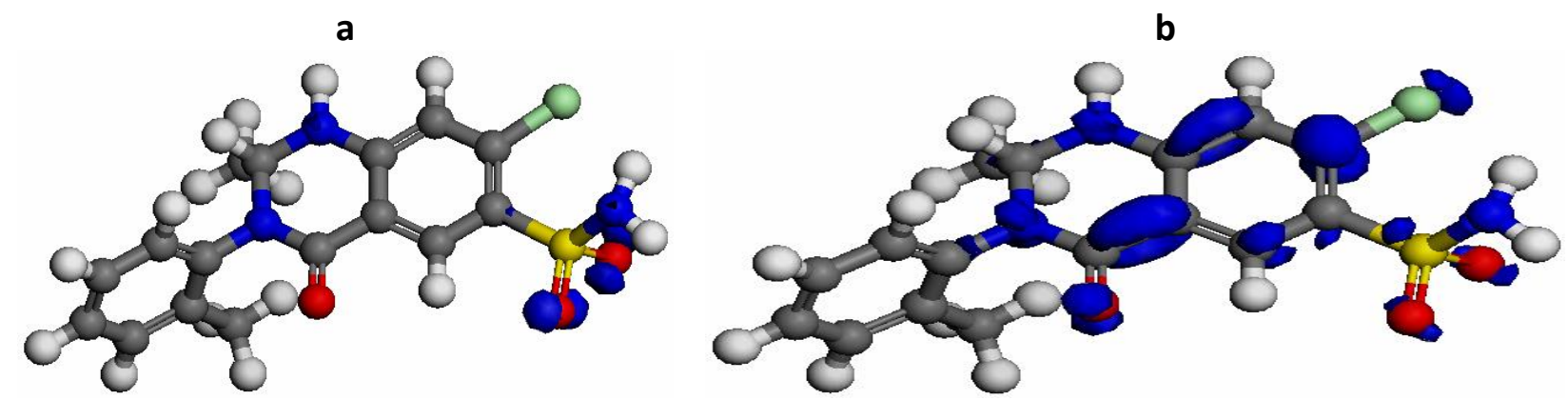

Figure 6. Fukui function of quinazoline derivative: (a) $f,(b) f^{+}$.

The highest negative values of $\left(f^{-}\right)$show the preferred site for electrophilic attack and this occurs in the nitro group of studied heteroatom compound shown in Figure 6, while the preferred site for nucleophilic attack is in alkenes carbon atom $\mathrm{C} 7$ of the studied molecule shown in Figure 6. During adsorption or bond formation, the electrons are expected to transfer from HOMO to LUMO $[46,47]$. Generally, shorter bond length is less reactive than longer bond length and also, multiple bond length is more reactive than the single bond length. Based on this principle the bond lengths of the studied quinazoline derivative are seen as their degree of reactivity and are bolded in Table 7 [43,44].

Table 7. DFT calculated values of bond lengths, and Fukui $\left(f^{-}\right)$and Fukui $\left(f^{+}\right)$indices for the studied heterocyclic inhibitor compound.

\begin{tabular}{ccccc}
\hline Atom & Bond & Length, & $f^{-}$ & $f^{+}$ \\
\hline C1 & C1-C2 & 1.398 & -0.001 & -0.001 \\
\hline C2 & C2=C3 & 1.396 & 0.004 & 0.005 \\
\hline C3 & C3-C4 & 1.398 & 0.007 & 0.009 \\
\hline C4 & C4=C5 & 1.404 & 0.004 & 0.005 \\
\hline C5 & C5-C6 & 1.506 & -0.002 & -0.003 \\
\hline C6 & C5-C7 & 1.420 & -0.001 & -0.002 \\
\hline C7 & C7-N8 & 1.441 & -0.014 & -0.023 \\
\hline N8 & N8-C9 & 1.475 & 0.045 & 0.055 \\
\hline C9 & C9-C10 & 1.520 & -0.02 & -0.021 \\
\hline C10 & N8-C11 & 1.375 & -0.007 & -0.01 \\
\hline C11 & C11-C12 & 1.469 & 0.007 & 0.043 \\
\hline C12 & C12-C13 & 1.392 & 0.023 & 0.019 \\
\hline C13 & C13-N14 & 1.429 & 0.011 & 0.025 \\
\hline N14 & C12=C15 & 1.408 & 0.042 & 0.049 \\
\hline C15 & C1=C7 & 1.401 & 0.005 & 0.019 \\
\hline C16 & C15-C16 & 1.401 & 0.001 & 0.002 \\
\hline C17 & C16=C17 & 1.409 & 0.007 & 0.077 \\
\hline C18 & C17-C18 & 1.397 & 0.023 & -0.046 \\
\hline S19 & C18=C13 & 1.399 & 0.065 & 0.018 \\
\hline N20 & C16-S19 & 1.814 & 0.063 & 0.053 \\
\hline O21 & S19-N20 & 1.758 & 0.181 & 0.051 \\
\hline O22 & S19=O21 & 1.546 & 0.17 & 0.077 \\
\hline O23 & S19=022 & 1.546 & 0.027 & 0.122 \\
\hline C24 & C11=023 & 1.220 & 0.04 & \\
\hline & & & & \\
\hline
\end{tabular}




\section{Mechanism of corrosion inhibition}

The actual corrosion inhibition mechanism in acidic $(\mathrm{HCl})$ medium by an inhibitor molecule occurs through the following modes: (a) electrostatic attraction between the charged molecules and charged metal, (b) interaction of uncharged electron pairs of the molecule with metal, (c) Interaction of $\pi$ electrons with metal, (d) combination of (a) and (c) [48]. The inhibitor molecule may block anodic, cathodic, or both sites through the process of adsorption, preventing anodic metal dissolution and corresponding cathodic reaction (such as hydrogen evolution reaction produced when a metal is immersed in $\mathrm{HCl}$ solution). A small degree of hydration present in chloride ions might draw excess negative charges around the metal interface and promote more positively charged molecules of the inhibitor. The synergy between adsorbed chloride ions and quinazoline is lead to the adsorption process; quinazoline can be adsorbed on the metal surface, requiring the displacement of water molecules from the mild steel surface and the exchange of electrons between the atoms of nitrogen or oxygen and iron. The adsorption of the inhibitor molecule on the mild steel surface is due to the donor-acceptor interactions between $\pi$-electrons of the aromatic ring and the vacant $d$ orbital of iron, Figure 7 shows a schematic diagram of the proposed inhibition adsorption mechanism of quinazoline on mild steel in the solution of $\mathrm{HCl}$.

Generally, corrosion of mild steel in the blank $\mathrm{HCl}$ solution is initially slowed down due to $\mathrm{HCl}$ ionization and formation of chloride ions which adsorb on the surface. The corrosion mechanism that has already been suggested for anodic iron dissolution in $\mathrm{HCl}$ solution can be described as $[49,50]$ :

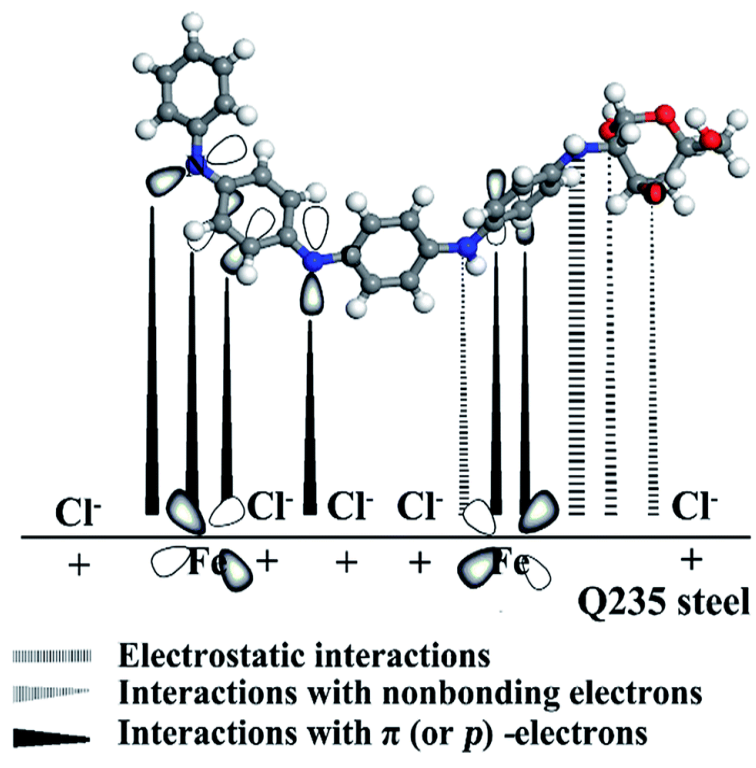

$\mathrm{Fe}+\mathrm{Cl}^{-} \rightarrow\left(\mathrm{FeCl}^{-}\right)_{\text {ads }}$

$\left(\mathrm{FeCl}^{-}\right)_{\text {ads }} \rightarrow(\mathrm{FeCl})_{\text {ads }}+\mathrm{e}^{-}$

$(\mathrm{FeCl})_{\text {ads }}+\mathrm{e}^{-} \rightarrow \mathrm{FeCl}^{+}+\mathrm{e}^{-}$

$\mathrm{FeCl}^{+}+\mathrm{e}^{-} \rightarrow \mathrm{Fe}^{2+}+\mathrm{Cl}^{-}$
Figure 7. Schematic representation of adsorption modes of quinazoline derivative molecule at mild steel surface.

Anodic dissolution in $\mathrm{HCl}$ solution is accompanied by cathodic hydrogen evolution reaction according to the following reaction pathway $[49,50]$ :

$$
\begin{aligned}
& \mathrm{Fe}+\mathrm{H}^{+} \rightarrow\left(\mathrm{FeH}^{+}\right)_{\text {ads }} \\
& \left(\mathrm{FeH}^{+}\right)_{\text {ads }}+\mathrm{e}^{-} \rightarrow(\mathrm{FeH})_{\text {ads }} \\
& (\mathrm{FeH})_{\mathrm{ads}}+\mathrm{H}^{+}+\mathrm{e}^{-} \rightarrow \mathrm{Fe}+\mathrm{H}_{2}
\end{aligned}
$$


In acidic solution, inhibitor molecules can be protonated easily. Physical adsorption may take place due to electrostatic interaction between protonated inhibitor molecule and negatively charged chloride species already present at the metal surface, while chemical adsorption is related to donor-acceptor interactions between inhibitor and low energy d-orbital of metal (Fe).

\section{Comparison of inhibition efficiency obtained by different methods}

Inhibition efficiencies (IE) obtained from weight loss (WL), potentiodynamic polarization (PDP) and electrochemical impedance spectroscopy (EIS) measurements are compared in Figure 8, showing good correlation of the obtained results.

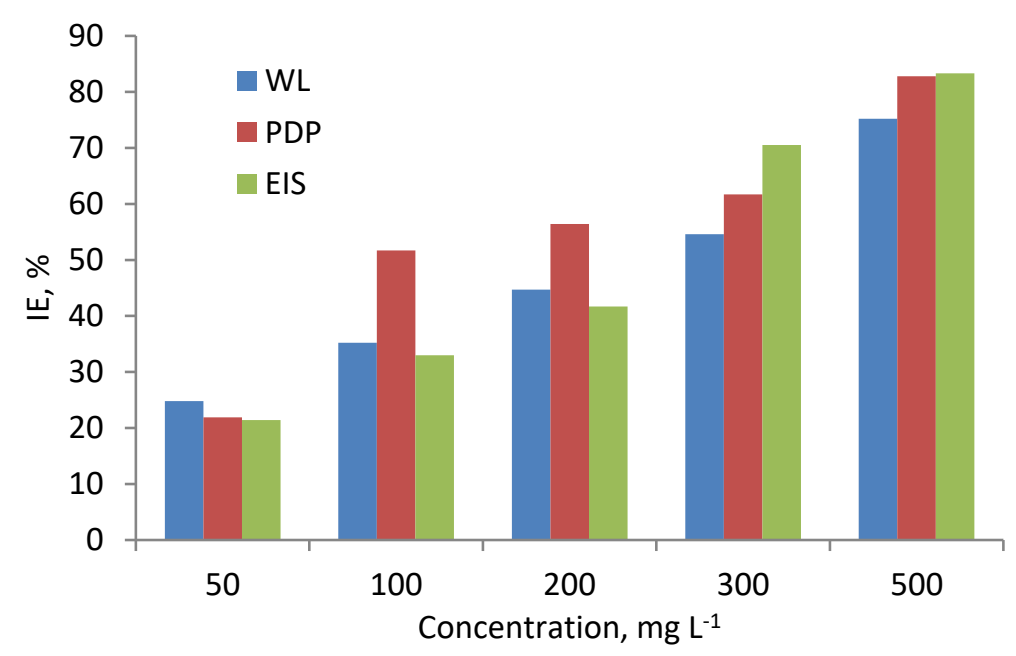

Figure 8. Comparison of inhibition efficiencies (IE) obtained by different methods for mild steel in $0.02 \mathrm{M} \mathrm{HCl}$ at different concentrations of quinazoline derivative.

The results obtained by all three techniques showed the same trends in the variation of corrosion rate and inhibition efficiency with increase of inhibitor concentration. Certain differences observed in the results obtained from weight loss and electrochemical techniques may be attributed to the specificity of each particular technique. Thus, weight loss measurements give average corrosion rates, while electrochemical measurements give instantaneous corrosion rates [51]. In Table 8, corrosion inhibition performance of some other drugs already applied for mild steel corrosion protection [2631,52], are compared. It can be observed from data in Table 8 that quinazoline, which is a derivative of metolazone drug, provides a reasonable corrosion inhibition efficiency behavior, compared to other drugs tested for corrosion inhibition of mild steel.

Table 8. Comparative chart listing performances of some other drugs acting as corrosion inhibitors of mild steel.

\begin{tabular}{|c|c|c|c|c|}
\hline Drug name & Electrolyte & Mode of adsorption & $\begin{array}{c}\text { Optimum IE at } \\
\text { inhibitor concentration }\end{array}$ & Ref. \\
\hline Norfloxacin & $0.1 \mathrm{M} \mathrm{H}_{2} \mathrm{SO}_{4}$ & Langmuir adsorption isotherm & $95.8 \%$ at $0.5 \mathrm{~g} / \mathrm{L}$ & [26] \\
\hline Metronidazole & $0.5 \mathrm{M} \mathrm{HCl}$ & $\begin{array}{c}\text { Mixed-type inhibitor / } \\
\text { Langmuir adsorption isotherm }\end{array}$ & $80.0 \%$ at 400 ppm & [27] \\
\hline Cephalexin & $0.1 \mathrm{M} \mathrm{HCl}$ & Langmuir adsorption isotherm & $80 \%$ at $13.0 \times 10^{-3} \mathrm{M}$ & [28] \\
\hline $\begin{array}{l}\text { Chloroquine } \\
\text { diphosphate }\end{array}$ & $0.1 \mathrm{M} \mathrm{HCl}$ & Langmuir adsorption isotherm & $80 \%$ at $4.65 \times 10^{-4} \mathrm{M}$ & [29] \\
\hline Tramadol & $0.5 \mathrm{M} \mathrm{HCl}$ & $\begin{array}{c}\text { Mixed-type inhibitor / } \\
\text { Langmuir adsorption isotherm }\end{array}$ & $82.6 \%$ at $2.16 \times 10^{-3} \mathrm{M}$ & [30] \\
\hline Dapsone & $1 \mathrm{M} \mathrm{HCl}$ & Langmuir adsorption isotherm & $93.3 \%$ at $400 \mathrm{ppm}$ & [31] \\
\hline $\begin{array}{l}\text { Quinazoline derivative } \\
\text { (Metolazone) }\end{array}$ & $0.02 \mathrm{M} \mathrm{HCl}$ & $\begin{array}{c}\text { Mixed-type inhibitor/ } \\
\text { Langmuir adsorption isotherm }\end{array}$ & $83.3 \%$ at $500 \mathrm{mg} / \mathrm{L}$ & $\begin{array}{c}\text { Present } \\
\text { study }\end{array}$ \\
\hline
\end{tabular}




\section{Scanning electron microscopy (SEM)}

The level of mild steel degradation was scrutinized using scanning electron microscopy (SEM) test. As shown in Figure 9, mild steel in the blank $\mathrm{HCl}$ solution exhibits visible and dark pits due the corrosive nature of acid (Figure 9a), while the surface nature of the steel in the inhibited media shows a smooth and bright surface compared to the blank sample (Figure 9b). This phenomenon of improved smoothness is attributed to adsorption of the active molecules of quinazoline derivative on the metal surface [50-53].
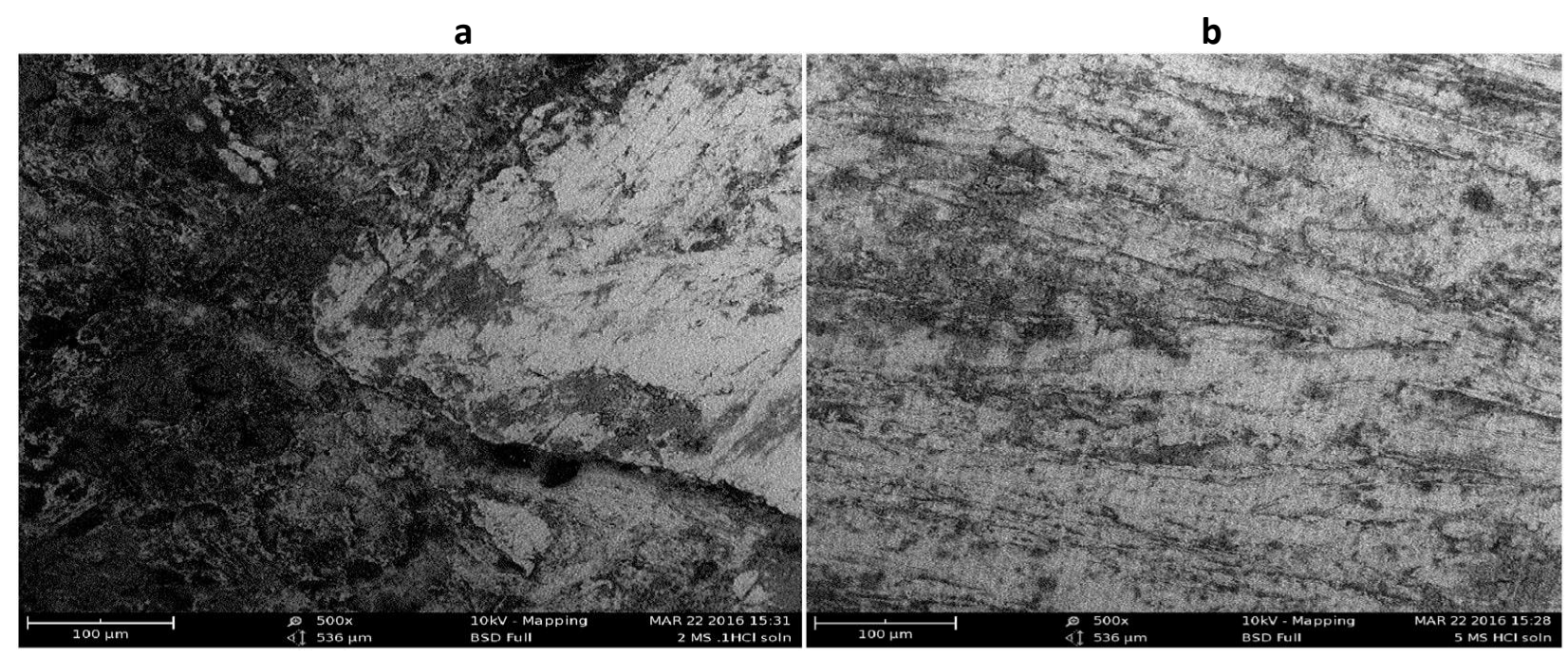

Figure 9. SEM images of mild steel surface after immersion period of 24 hours in: (a) uninhibited $\mathrm{HCl}$ solution and (b) inhibited $\mathrm{HCl}$ solution.

\section{Conclusions}

A new insight into corrosion inhibition of mild steel in $\mathrm{HCl}$ solution by a novel drug molecule metolazone, a quinazoline derivative (chloro-2-methyl-4-oxo-3-0-tolyl-1,2,3,4-tetrahydroquinazoline-6-sulfonamide), was provided using weight loss, electrochemical and theoretical studies. The results obtained using different experimental techniques were found to be in good mutual agreement, and comparable with literature data on different drug molecules already tested for mitigation of mild steel corrosion. It was found that the studied quinazoline derivative behaves as a mixed type inhibitor, while its inhibition efficiency increases with increased concentration of the inhibitor. Corrosion inhibition is realized by adsorption of quinazoline derivative on mild steel surface obeying Langmuir adsorption isotherm. The negative sign of the free energy change of adsorption indicated that adsorption of the studied compound on mild steel surface is a spontaneous process proceeding by the physical adsorption mechanism. This was supported by the values of other thermodynamic corrosion parameters (activation energy, activation enthalpy and activation entropy) that suggest slowing down of corrosion by spontaneous adsorption of inhibitor. The computational quantum chemistry studies confirmed that the studied molecule is adsorbed on the metal surface through nitro functional groups. Also, a pronounced effect of inhibitor adsorption on the mild steel surface in $\mathrm{HCl}$ solution was confirmed by SEM images, showing surface smoothness being much improved by presence of quinazoline derivative inhibitor.

\section{References}

[1] R. S. Al-Moghrabi, A. M. Abdel-Gaber, H. T. Rahal, International Journal of Industrial Chemistry 9 (2018) 255-263.

[2] Z. Sanaei, M. Ramezanzadel, G. Bahlakeh, B. Ramezanzadel, Journal of Industrial and Engineering Chemistry 69 (2019) 18-31. 
[3] A. A. Khadom, A. N. Abd, N. A. Ahmed., South African Journal of Chemical Engineering 25 (2018) 13-21.

[4] T. He, W. Emori, R.-H. Zhang, P. Okafor, M. Yang, C. R. Cheng, Bioelectrochemistry 130 (2019) 107332 https://doi.org/10.1016/j.bioelechem.2019.107332.

[5] H. Yang, M. Zhang, A. Singh, International Journal of Electrochemical Science 13 (2018) 919144.

[6] N. O. Eddy, P. O. Ameh, N. B. Essien, Journal of Taibah University for Science 12(5) (2018) 545-556.

[7] E. Ogoko, A. Ogunsipe, Chemical Science Transactions 4(2) (2015) 503-515.

[8] A. S. Fouda, G. Y. Elewady, H. A. Mostafa, S. Habbouba, African Journal of Pure and Applied Chemistry 7(5) (2013) 198-207.

[9] H. M. M. Al-tamimy, S. M. H. Al-Majidi. IOSR-Journal of Applied Chemistry 9(8) (2016) 36-44.

[10] N. M. Hashim, A. A. Rahim, H. Osman, P. B. Raja, Chemical Engineering Communications 199 (2012) $751-766$.

[11] M. Rbaa, M. Galai, A. S. Abousalem, B. Lakhrissi, M. EbnTouhami, I. Warad, A. Zarrouk. Ionics 26 (2019) 503-522. https://doi.org/10.1007/s11581-019-03160-9.

[12] A. Chaouiki, H. Lgaz, S. Zehra, R. Salghi, I. M. Chung, Y. El Aoufir, K. S. Bhat, I. H. Ali, S. L. Gaonkar, M. I. Khan, H. Oudda, Journal of Adhesion Science and Technology 33(9) (2019) 921-944.

[13] A. Kadhim, A. K. Al-Okbi, D. M. Jamil, A. Qussay, A. A. Al-Amiery, T. S. Gaaz, A. A. H. Kadhum, A. B. Mohamad, M. H. Nassir, Results in Physics 7 (2017) 4013-4019.

[14] S. Öztürk, Russian Journal of Organic Chemistry 55 (2019) 245-249.

[15] A. S. Fouda, A. M. El-Desoky, H. M. Hassan, International Journal Electrochemical Science 8 (2013) 58665885.

[16] C. B. Pradeep Kumar, M. K. Prashanth, K. N. Mohana, M. B. Jagadeesha, M. S. Raghu, N. K. Lokanath, Mahesha, M. K. Yogesh Kumar, Surfaces and Interfaces 18 (2020) 100446 https://doi.org/10.1016/j.surfin.2020.100446.

[17] S. Karthikeyan, P. A. Jeeva, K. Raja, Journal of Chemical and Pharmaceutical Research 7(1) (2015) $906-912$.

[18] F. E. Abeng, M. E. Ikpi, K. Uwakwe, G. Ikpi, International Research Journal of Pure and Applied Chemistry 15(3) (2017) 37782 https://doi.org/10.9734/IRJPAC/2017/37782.

[19] I. A. Akpan, N. O. Offiong, International Journal of Chemistry and Material Research 2(3) (2014) 23-29.

[20] P. O. Ameh, P. Ukoha, P. Ejikema, N. O. Eddy, Industrial Chemistry 2(2) (2016) 119 https://doi.orgL10.4172/2469-9764.1000119.

[21] E. M. Attia, Journal of Basic and Applied Chemistry 5 (1) (2015) 1-15.

[22] S. A. Umoren, I. B. Obot, E. E. Ebenso, P. C. Okafor, O. Ogbobe, E. E. Oguzie, Anti-Corrosion Methods and Materials 53(5) (2006) 277-282.

[23] O. O. Fadare, A. E. Okoronkwo, E. F. Olasehinde, African Journal of Pure and Applied Chemistry 10(1) (2016) 8-22.

[24] I. Naqvi, A. R. Saleemi, S. Naveed, International Journal of Electrochemical Science 6(1) (2011) $146-161$.

[25] M. Ramezanzadeh, G. Bahlakeh, B. Ramezanzadeh, M. Rostami, Journal of Industrial and Engineering Chemistry 72 (2019) 474-490.

[26] N. O. Eddy, S. R. Stoyanov, E. E. Ebenso, International Journal of Electrochemical Science 5 (2010) 1127-1150.

[27] I. B. Obot, E. E. Ebenso, M. M. Kabanda, Journal of Environmental Chemical Engineering 1(3) (2013) 431-439.

[28] A. Akpan, N. O. Offiong, American Journal of Chemistry and Materials Science 1(1) (2014) 1-6.

[29] S. U. Ofoegbu, P. U. Ofoegbu, ARPN Journal of Engineering and Applied Science 7(3) (2012) $272-276$.

[30] R. A. Prabhu, A. V. Shanbhag, T. V. Venkatesha, Journal of Applied Electrochemistry 37 (2007) $491-497$.

[31] A. Singh, A. K. Singh, M. A. Quraishi, Open Electrochemical Journal 2 (2010) 43-51.

[32] I. B. Obot, N. O. Obi-Egbedi, S. A. Umoren, E. E. Ebenso, Chemical Engineering Communications 198(5) (2011) 711-725.

[33] V. C. Anadebe, O. D. Onukwuli, M. Omotioma, N. A. Okafor, South African Journal of Chemistry 71 (2018) 51-61.

[34] R. Idouhli, A. N'AitOusidi, Y. Koumya, A. Abouelfida, A. Benyaich, A. Auhmani, M. Y. Aitltto, International Journal of Corrosion (2018) 9212705 https://doi.org/10.1155/2018/9212705.

[35] G. Y. Elewady, International Journal of Electrochemical Science 3 (10) (2008) 1149-1161.

[36] M. M. Kabanda, L. C. Murulana, M. F. Ozcan, I. D. Karadag, B. I. Obot, E. E. Ebenso, International Journal of Electrochemical Science 7(6) (2012) 5035-5056.

[37] G. Gao, C. Liang, Electrochimica Acta 52(13) (2007) 4554-4559.

[38] P. O. Ameh, P. U. Koha, N. O. Eddy, Chemical Science Journal 6 (2015) 100 https://doi.org/10.4172/21503494.1000100.

[39] A. Ansari, M. Znini, I. Hamdani, L. Majidi, A. Bouyanzer, B. Hammouti, Journal of Material and Environmental Science 5(1) (2014) 81-94. 
[40] C. Arunagiri, A. Subashini, M. Saranya, P. T. Muthiah. Indian Journal of Applied Research 3 (2013) 78-81.

[41] S. Chen, S. Scheiner, T. Kar, U. Adhikari, International Journal of Electrochemical Science 7(8) (2012) 71287139.

[42] E. E. Ebenso, D. A. Isabirye, N. O. Eddy, International Journal of Molecular Science 11 (2010) 2473-2498.

[43] N. O. Eddy, E. E. Ebenso, U. J. Ibok. Journal of Applied Electrochemistry 40 (2010) 445-456.

[44] G. Raja, K. Saravanan, S. Sivakumar, Rasayan Journal of Chemistry 8(1) (2015) 8-12.

[45] F. E. Abeng, M. E. Ikpi, V. E. Okpashi, O. A. Ushie, M. E. Obeten, Journal of Electrochemical Science and Engineering 10(3) (2020) 235-244.

[46] A. A. Siaka, N. O. Eddy, S. O. Idris, L. Magaji, Z. N. Garba, I. S. Shabanda, International Journal of Modern Chemistry 4(1) (2013) 1-10.

[47] S. Shahabi, P. Norouzi, M.R. Ganjali. International Journal of Electrochemical Science 10(3) (2015) 26462662.

[48] M. R. Vinutha, T. V. Venkatesha, Portugaliae Electrochimica Acta 34(3) (2016) 157-184.

[49] S. Chen, B. Zhu, X. Liang, International Journal of Electrochemical Science 15(1) (2020) 1-15.

[50] N. Shet, R. Nazareth, P. A. Suchetan, Chemical Data Collection 20 (2019) 100209 https://doi.org/10.1016/i.cdc.2019.100209.

[51] A. M. Guruprasad, H. P. Sachin, G. A. Swetha, B. M. Prasanna, Surface and Interface 19 (2020) 100478 https://doi.org/10.1016/i.surfin.2020.100478.

[52] A. Samide, Journal of Environmental Science and Health Part A 48(2) (2013) 159-165.

[53] F. E. Abeng, V. C. Anadebe, V. D. Idim, M. M. Edim, South African Journal of Chemistry 73 (2020) 125-130.

(C)2021 by the authors; licensee IAPC, Zagreb, Croatia. This article is an open-access article distributed under the terms and conditions of the Creative Commons Attribution license (https://creativecommons.org/licenses/by/4.0/) 